\title{
Competências digitais e práticas de ensino de PLE a hispanofalantes em contexto universitário online de emergência
}

Competencias digitales y prácticas de enseñanza de PLE a hispanohablantes en contexto universitario online de emergencia

\section{Ana Laura dos Santos Marques}

Universidad De Santiago de Chile - USACH - Santiago - Chile

\begin{abstract}
Resumo: Neste artigo, apresentamos quatro recursos didáticos virtuais configurados para a exposição de conteúdos, interação, colaboração e avaliação em atividades de português como língua estrangeira (PLE) a hispanofalantes numa universidade pública chilena. A descrição e o emprego desses recursos são associados ao contexto institucional e aos resultados de aprendizagem estabelecidos por suas grades curriculares. Nosso objetivo é explorar como o desenho e a realização das atividades para o ensino de PLE impacta o processo de letramento digital, tanto em relação a professores como em relação a estudantes. Para isso, consideramos pesquisas publicadas acerca do emprego das TIC's no ensino e aprendizagem de línguas estrangeiras nos últimos 20 anos (PAIVA, 2001; LEFFA, 2006; GRABE \& GRABE, 2005; TOUR, 2015; RODRIGUES, MUENCHOW \& RIBAS, 2017), destacando suas implicações na relação com os materiais didáticos, com o planejamento das aulas, com a interação e com a multidimensionalidade característica de cenários em linha. Reconhecemos que, ao longo do tempo, termos como blended learning e aprendizagem online passaram a ser comuns para professores e estudantes, embora dependentes de seus interesses e competências digitais. De forma urgente e acelerada o ano 2020, marca uma mudança com relação ao uso das TIC's nas práticas educativas em geral, devido ao estabelecimento do ensino remoto de emergência vivenciado durante a pandemia do Sars-CoV-2. Precisamente, nossas reflexões apontam à forma em que, a partir desse contexto, instalam-se e projetam-se transformações na educação terciária de línguas estrangeiras em condições menos emergenciais, demandando o desenvolvimento de competências digitais de alunos e de professores.
\end{abstract}

Palavras-chave: Competências digitais. PLE a hispanofalantes. Ensino remoto de emergência

\begin{abstract}
En este artículo, presentamos cuatro recursos didácticos virtuales configurados para exposición de contenidos, interacción, colaboración y evaluación en actividades de portugués como lengua extranjera (PLE) a hispanohablantes en una universidad pública chilena. La descripción y el empleo de estos recursos están asociados con el contexto institucional y con los resultados de aprendizaje establecidos en su curriculum. Nuestro objetivo es explorar cómo el diseño y la realización de las actividades para la enseñanza de PLE impacta el proceso de literacidad digital, de profesores y estudiantes. Para ello, consideramos investigaciones publicadas acerca del empleo de las TIC's en la enseñanza y en el aprendizaje de lenguas extranjeras en Ios últimos 20 años (PAIVA, 2001; LEFFA, 2006; GRABE \& GRABE, 2005; TOUR, 2015; RODRIGUES, MUENCHOW \& RIBAS, 2017), destacando sus implicaciones en los materiales didácticos, diseño de las clases, interacción y multidimensionalidad característica de escenarios online. Reconocemos que, a lo largo de estos años, términos como blended learning y aprendizaje online se volvieron comunes para profesores y estudiantes, aunque dependientes de sus iniciativas personales. De forma urgente y acelerada, el año 2020 marca un cambio en relación con el uso de las TIC's en las prácticas educativas en general debido al establecimiento del contexto de enseñanza remota de emergencia durante la pandemia del Sars-CoV-2. Precisamente, nuestras reflexiones apuntan a la forma en que, a partir de este contexto, se instalan y se proyectan transformaciones en la educación terciaria de lenguas extranjeras en condiciones menos urgentes, demandando el desarrollo de competencias digitales de alumnos y profesores.
\end{abstract}

Keywords: Competencias digitales. PLE a hispanohablantes. Enseñanza remota de emergencia. 


\section{Introdução}

As especificidades em torno do ensino e da aprendizagem de português a hispanofalantes (e viceversa) foram e continuam sendo temas de pesquisa ao longo de várias décadas e, sobretudo, tentam responder às necessidades de professores e aprendizes geradas desde os âmbitos políticos, econômicos, educacionais e culturais. Aspectos como intercompreensão, aproximações e contrastes gramaticais, criação, avaliação e publicação de materiais, interculturalidade e formação de professores permanecem como constantes nos enfoques de pesquisas desenvolvidas no Brasil (DELL'ISOLA, 2002; 1998; FERREIRA, 1998; ALMEIDA FILHO, 1995; 2013; JÚDICE, 2002; 2013; MENDES, 2011; MARQUES, 2017) e no contexto europeu, Portugal e Espanha (ALONSO REY, 2004; 2012; GROSSO, SOARES, SOUZA e PASCUAL, 2011). Adicionam-se à variável proximidade linguística português e espanhol questões relacionadas com uma diversidade de propósitos e abordagens pedagógicas, bem como imposições contextuais vinculadas com diferentes realidades das instituições educativas, o que torna 0 ensino dessas duas línguas especialmente exigente.

Corroborando que as pautas das pesquisas relacionadas com o par português-espanhol acompanham e tentam dar respostas a um grande número de temáticas, o atual contexto de ensino online devido à pandemia do Sars-CoV-2, abre novas perspectivas de pesquisa ao exigir esforços de professores e estudantes em uma adaptação forçada a uma nova modalidade de aulas. Para explorar de modo sistemático essa experiência de ensino, torna-se fundamental um olhar atento a variáveis que sempre estiveram presentes nas pesquisas da área de PLE, como línguas próximas, interação, materiais ou recursos para a aprendizagem e avaliação, acrescidas das particularidades dos contextos virtuais.

Neste artigo, a emergência do ensino online de português numa universidade pública chilena insere o português como língua estrangeira (PLE) nas discussões sobre a acelerada transformação do ensino universitário de línguas estrangeiras. Nas nossas reflexões, o uso das tecnologias de informação e comunicação - TIC's, a complexidade em mesclar conhecimentos didáticos e disciplinares com 0 desenvolvimento de competências digitais são referidas com o fim de compreender melhor os desafios e as respostas possíveis surgidas dessa emergência. Com isso, pretendemos refletir sobre novas formas de entender o ensino da língua, a colaboração na aprendizagem e o letramento digital, nosso, como professores, e dos estudantes.

Desde o nosso contexto de docência de português como língua estrangeira para a formação de tradutores espanhol-inglês-português numa universidade pública do Chile, analisamos no presente artigo quatro recursos didáticos virtuais para a configuração de atividades desenvolvidas na disciplina Gramática Contrastiva Português-Espanhol, os quais compreendem diferentes possibilidades sobre exposição de conteúdos, interação, colaboração e avaliação online. Nosso objetivo é explorar como o desenho das atividades para $o$ ensino e a aprendizagem de PLE impacta o processo de letramento digital tanto para professores como para os alunos em suas aulas virtuais. Sendo assim, as perguntas que norteiam o presente trabalho são: i. Em que medida os recursos exemplificados representariam "transformações" na abordagem de conteúdos de PLE a hispanofalantes? ii. Como os recursos exemplificados relacionam competências acadêmicas, desenvolvimento de língua e letramento digital de professores e estudantes?

Este artigo se estrutura da seguinte forma: em primeiro lugar, revisamos alguns estudos acerca do emprego das TIC's na sala de aula de línguas estrangeiras e mostramos como a área de PLE ainda carece de iniciativas e abordagens no âmbito virtual. Apresentamos e relacionamos com esses estudos 0 documento "Quadro europeu para a competência digital do professorado", DigCompEdu. Na seção Análise de recursos - descrição e avaliação, caracterizamos os recursos virtuais selecionados e seu potencial para aplicação na área de ensino de PLE, tanto em referência a aspectos relativos ao desenvolvimento de língua estrangeira como com o 
letramento digital de professores e estudantes. Por fim, na seção Considerações finais, tecemos nossas considerações sobre a relação identificada entre competências digitais e as práticas de ensino de PLE a hispanofalantes desde o nosso contexto de trabalho.

\section{Entre TIC's, ensino remoto de emergência} e letramento digital: uma breve revisão bibliográfica

A incorporação de tecnologias de informação e comunicação (TIC's) ao ensino de línguas estrangeiras (LE) vem sendo abordada por diversas pesquisas ao longo de décadas. De modo geral, definem-se como "um conjunto de ferramentas digitais para a comunicação, em geral, criadas e suportadas por meios informáticos" (BURBAT, 2015, p. 39). Dada a diversidade de recursos que se desenvolvem com o uso da tecnologia, é comum reconhecermos, que em termos de TIC's aplicadas ao ensino, "la oferta es tan enorme que da la sensación de que es prácticamente imposible, estar a la última, también debido al progreso tan acelerado en el ámbito de la informática" (BURBAT, 2015, p. 38)

No contexto brasileiro, Paiva (2001), já mostrava como o uso da internet enriquecia o processo de aquisição do inglês, ressaltando suas grandes diferenças com relação aos materiais didáticos disponíveis na época, a saber: sua "multidimensionalidade" e sua "não linearidade" (PAIVA, 2001, p. 96-97). Para esta pesquisadora, a revolução observada no ensino de línguas com o advento da web seria notória, inovando essas práticas em termos de interatividade nos numerosos recursos encontrados para vivenciar a língua de forma sincrónica com outros usuários.

Em documento publicado no ano 2004 pela UNESCO, Information and Communication Technologies in the teaching and learning foreign languages, state-of-the-art, needs and perspectives, já se salientavam as vantagens, a importância do professor e dos espaços de interação por meio das TIC's como enriquecedores dos processos de ensino e aprendizagem de línguas estrangeiras e pretendia "mostrar como esse entorno virtual poderia contribuir à compreensão intercultural" (UNESCO, Analytical Survey Working Group, 2004, p. 2). Seguindo essas reflexões, no ano 2005, Grabe e Grabe propunham em Integrating Technology for Meaningful Learning orientações concretas para professores acerca do uso da tecnologia em suas práticas docentes, como o aproveitamento de páginas web, recursos para apresentação e interação de estudantes e professores, intercâmbios de informação e implementação de ferramentas digitais em contextos de sala de aula.

Em concreto, décadas de uso, aperfeiçoamento, novas necessidades e aplicações didáticas, à medida que as TIC's passam a incorporarse na vida cotidiana, resultam num incremento natural nas pesquisas e publicações da área (LEFFA, 2006; JARAMILLO, 2005; COSTA e PERALTA, 2007; TUMOLO, 2014; RODRIGUES, MUENCHOW E RIBAS, 2017). Como podemos apreciar, aprender e ensinar línguas estrangeiras passaram a ser indissociáveis dos recursos virtuais que se desenvolveram e continuam se desenvolvendo com os avanços tecnológicos.

Observamos alguns aspectos comuns nas pesquisas acerca do ensino e aprendizagem de línguas estrangeiras que também coincidem com preocupações de professores, estudantes e do mercado editorial, a saber: a) como o uso de TIC's se converte em uma alternativa potente para o inovar e desenvolver o ensino de línguas estrangeiras; b) como levar adiante e beneficiar-se de práticas pedagógicas associadas a recursos tecnológicos disponíveis, e c) como observar/avaliar a aprendizagem dos estudantes em ambientes virtuais. De fato, a importância de que esses recursos estejam em sala de aula há muito já não é objeto de questionamento, posto que nossas dinâmicas sociais incorporaram rapidamente a tecnologia para a comunicação. Porém, ainda é necessário avaliar de forma constante os usos de TIC's em contextos formais de ensino de línguas estrangeiras, fato que implica tanto a observação de competências digitais de professores e estudantes como as condições institucionais para suas aplicações e a vinculação dessas práticas com recursos 
autênticos para o desenvolvimento linguístico, de modo a permitir também a conformação de espaços para que TIC's aplicadas à pedagogia se aperfeiçoem.

Ao referirmos às vantagens das TIC's para o ensino de línguas estrangeiras, um dos argumentos para a sua presença em sala de aula é a noção de multiletramentos, a qual modificou o propósito do ensino de línguas, materna e adicionais, ao enfatizar a linguagem como ato de produção de significados. Para compreender a importância desse conceito, seu surgimento no fim da década de 1990 propunha a incorporação de práticas sociais emergentes de linguagem, isto é, compreendeu-se que usar a língua em sociedade significa também acompanhar 0 desenvolvimento de tecnologias que vão conformando nossa forma de comunicar e significar em nossas interações (LOTHERINGTON e JENSON, 2011). Sendo assim, 0 ensino deveria visar 0 desenvolvimento de competências para a participação em práticas emergentes: colaboração, interação e criatividade conectados com o domínio das TIC`s (TOUR, 2015). Essas últimas, entendidas como essenciais para que 0 indivíduo aceda ao conhecimento e participe de sua (re)criação.

Professores de LE certamente irão reconhecer que suas aulas incorporam o uso da tecnologia, considerando as situações particulares e limitações contextuais que devem enfrentar em seus ambientes de trabalhos. De forma recorrente suas aulas se estruturam em apresentações em PowerPoint, mantêm comunicação via e-mail com os estudantes, para a entrega e avaliação de tarefas e utilizam recursos de aprendizagem online, como buscadores, dicionários, gramáticas, blogs, vídeos, foros e chats. $\bigcirc$ fato de a tecnologia já estar presente nas práticas docentes por meio desses usos não necessariamente implica que professores e instituições estavam preparados para enfrentar o "ensino remoto de emergência" (HODGES, MOORE, LOCKEE, TRUST e BOND, 2020) vivenciado no contexto de pandemia gerado pelo Sars-CoV-2. Todo o referencial teórico acerca do desenho de cursos para o ensino à distância, blended learning, aprendizagem em linha, entre outras distinções encontradas na literatura, parece confundir-se, ao mesmo tempo em que exige capacitação permanente dos docentes para entender como interação, práticas e avaliações precisam ser redesenhadas nesse contexto.

Esse contexto de ensino remoto de emergência passou a requerer dos professores de línguas estrangeiras o domínio de competências que sempre ficavam postergadas para circunstâncias futuras, salvo em exceções de motivação e de interesse próprios. Além disso, se as TIC's eram um apoio ou complemento ao ensino presencial (SILVA, 2013; TOUR; 2015), as motivações atuais nos obrigam a reorientar nossa mirada acerca do seu uso. Nessa nova realidade, o ensino remoto de emergência acelerou a necessidade de capacitação docente e impôs o letramento digital no centro das discussões. Em resumo, esse contexto reconfigura as necessidades docentes: o domínio de competências digitais se mescla com competências acadêmicas e pedagógicas. Em termos de ensino de PLE a hispanofalantes, esse acréscimo é, por certo, outro desafio que deve ser explorado com muita atenção.

\subsection{Competências digitais para o ensino de} línguas: um passo necessário

Quando nos referimos às necessidades surgidas devido ao contexto de ensino remoto de emergência, tendemos a concentrar-nos no imediato uso das TIC's para cumprir com os requerimentos institucionais de levar a cabo nossos programas de disciplinas, omitindo o fato de que há muito estão presentes em nosso quotidiano.

No ano 2017, a Comissão Europeia, por meio de seu Joint Research Centre, publica o Quadro de referência para Competências Digitais de Educadores, DigCompEdu - European Framework for the Digital Competences for Educators. Este documento reitera que a incorporação de tecnologias digitais representa não somente inovação nas práticas educativas, mas também possui outras funções: "melhorar o acesso à aprendizagem contínua ao longo da vida dos indivíduos e promover novas competências digitais requeridas para a inclusão profissional, pessoal e 
social" (European Framework for the Digital Competences for Educators, Joint Reserach Centre, 2017, p. 6).

O Quadro DigCompEdu assume que professores de todos os níveis educativos se enfrentam a demandas tecnológicas e requerem de um conjunto amplo de competências e estratégias digitais para sua atuação. Como objetivo, estabelece a intenção de proporcionar um quadro de referência geral para os desenvolvedores de modelos de competências digitais, governos e organismos nacionais e regionais, organizações educativas, formadores profissionais e os próprios educadores. Apesar de se fundamentar no contexto europeu, grande parte da proposta poderia ser adaptada e servir de orientação para a elaboração de documentos mais próximos a contextos locais ou regionais.

O DigCompEdu guarda algumas características em comum com o Quadro Comum Europeu de Referência para as Línguas, como por exemplo, a organização dos níveis de competência, considerando uma gradação de menos contato com ferramentas digitais e necessidade de orientação a um contato total e crítico quanto ao uso dessas ferramentas: A1Novato; A2- Exploradores; B1- Integradores; B2Expertos; C1- Líderes; C2- Pioneiros. Dessa forma, a progressão na competência digital corresponde a etapas de reflexão, uso, diversificação, reflexão e renovação.

Em seus descritores, há seis grandes áreas que abarcam um total de 22 competências, as quais articulam competências profissionais, pedagógicas e dos estudantes. Entender o impacto que essas competências oferecem para a formação contínua de professores, sua vinculação com o letramento digital e sua aplicação a contextos de ensino variados, com menos ou mais recursos materiais para a docência são parte importante da proposta do DigCompEdu. Não se trata apenas de desenvolver competências para inovar com o uso da tecnologia no ensino, mas também de promover a inclusão de indivíduos numa sociedade cada vez mais digital.

Considerar criticamente os descritores apresentados pelo quadro europeu DigCompEdu é parte importante do processo de desenvolvimento de competências digitais para o ensino de línguas. Longe de uma reprodução sem o reconhecimento das nossas limitações contextuais, sugerimos uma autoavaliação do que podemos, como professores de línguas, e do que nossos estudantes são capazes de produzir, tal como apresentamos na seção seguinte.

\section{Análise de recursos: descrição e avaliação}

Nesta seção, apresentamos a descrição e a análise da aplicação de quatro recursos virtuais utilizados na modalidade de ensino online de emergência na disciplina Gramática Contrastiva Português-Espanhol. Para isso, descrevemos, em linhas gerais, nosso contexto de ensino e aprendizagem de PLE e o planejamento da referida disciplina de forma online. As atividades exemplificadas correspondem a possibilidades de abordar, de forma remota, aspectos como interação, desenvolvimento de conteúdos por meio da língua e avaliação empregando recursos virtuais disponíveis e adaptados às necessidades do ensino de PLE a hispanofalantes em contexto de formação acadêmica.

\subsection{Contextualização}

O curso de graduação em Lingüística Aplicada a la Traducción (LAT) é o único no contexto universitário chileno que insere a língua portuguesa com propósitos acadêmicos, ou seja, como parte da formação disciplinar no âmbito do ensino terciário. Os estudantes que ingressam à universidade veem-se por primeira vez em situação de contato com o português com poucas e dispersas informações acerca da sua proximidade com o espanhol. Cabe destacar que no marco das políticas linguísticas nacionais, apenas a língua inglesa faz parte do curriculum da educação básica e média como língua estrangeira, o que permite assumir que os estudantes de LAT chegam à universidade com algum conhecimento dessa língua. Durante o primeiro ano, a grade curricular está organizada em um ciclo geral de introdução às línguas estrangeiras, português e japonês, nivelamento em 
inglês e de estudos em espanhol como língua materna. Após essa primeira etapa, os estudantes devem escolher uma das habilitações possíveis: inglêsespanhol-português ou inglês-espanhol-japonês.

A disciplina Gramática Contrastiva PortuguêsEspanhol faz parte da grade curricular do curso de graduação em LAT. Está estruturada como um curso presencial com quatro horas pedagógicas de trabalho direto semanais. Trata-se de uma disciplina de $3^{\circ}$ ano obrigatória para os estudantes que escolhem a habilitação língua portuguesa. Entre suas particularidades, podemos referir-nos à sua organização e aos resultados de aprendizagem previstos. Em termos de organização, a disciplina consiste em uma seleção de tópicos gramaticais em português e em espanhol que são abordados de forma contrastiva em língua portuguesa. Em outras palavras, os tópicos gramaticais selecionados são descritos em português, utilizando as gramáticas tradicional e descritiva como ponto de partida, contrastados com a língua espanhola e aplicados a pesquisas sobre seus usos e a prática da tradução. Ao mesmo tempo em que desenvolve o conhecimento metalinguístico dos estudantes, é também um espaço para a ampliação dos conhecimentos de língua portuguesa. Com relação aos resultados de aprendizagem, pretende-se que os estudantes desenvolvam sua capacidade de analisar, relacionar e sistematizar suas pesquisas linguísticas com relação ao par português-espanhol, ao mesmo tempo em que desenvolvem o registro acadêmico da língua portuguesa, isto é, falar sobre a língua na língua em um contexto de desenvolvimento de conteúdos para sua formação (SCHLEPPEGRELL, 2002; 2004). Dessa forma, ferramentas de busca, seleção e aprimoramento das habilidades orais e escritas em língua portuguesa se misturam como parte das atividades realizadas. É válido destacar também que, em condições de ensino presencial, o uso das TIC's em Gramática Contrastiva Português-Espanhol costuma ser um apoio informal e um complemento ao trabalho feito em sala de aula. Ao ter a sua modalidade de trabalho online, ressalta-se o potencial de uso dos recursos virtuais considerando a organização e os resultados de aprendizagem da referida disciplina.
Dado o estabelecimento da modalidade de ensino online de emergência para o primeiro semestre de 2020, escolas e universidades no país tiveram que adotar medidas e implementação virtual. Em particular, a Universidad de Santiago de Chile se preparou com a entrega de bolsas de conectividade e computadores a estudantes que necessitassem desse tipo de apoio. Igualmente, lançou uma série de iniciativas para a capacitação docente com relação ao uso da plataforma virtual da própria universidade, já existente e utilizada de forma bastante irregular por grande parte dos professores. Estabeleceu-se ainda um protocolo para a docência virtual, em que se priorizava a inclusão e a participação dos estudantes, por meio da gravação dos encontros, da disponibilização de recursos para estudos autônomos, das avaliações e do limite de tempo para as interações sincrônicas, não mais que sessenta minutos e dentro do horário das disciplinas ofertadas por cada unidade acadêmica. O calendário acadêmico também sofreu adaptações, o que incluiu um início tardio, em abril, e uma estrutura de quatro semanas consecutivas de trabalho remoto, seguidas por uma semana de pausa de atividades acadêmicas para garantir três aspectos definidos como essenciais para a prática virtual: i. avaliar e garantir que os estudantes pudessem acompanhar os conteúdos e participar das disciplinas; ii. permitir que os professores atualizassem seus cronogramas e adaptassem, em extensão e tempo, seus conteúdos e propostas de avaliação segundo os avances observados em suas práticas acadêmicas; iii. oferecer a professores e estudantes uma pausa necessária para gerar o bemestar emocional na comunidade educativa.

\subsection{Descrição e avaliação dos recursos}

Categorizamos os recursos exemplificados a seguir como ferramentas colaborativas digitais. Seu uso se relaciona tanto para que professor e estudantes construam conteúdos juntos, de forma sincrônica, ou para que o professor exponha temas, utilizando o potencial de quadro que estas ferramentas oferecem. Fundamentam a noção colaborativa desses recursos a teoria do conectivismo desenvolvida por Siemens 
(2005), segundo a qual a aprendizagem ocorre a partir do envolvimento dos aprendizes e suas decisões, articulando e inter-relacionando uma diversidade de informações por meio das conexões com os outros, virtuais ou presenciais. De modo concreto, o uso massivo da internet e das TIC's no ensino de línguas comprova a criação de espaços de interação para a aprendizagem, tal como ressaltam Hernández-Sellés, González- Sanmamedy e Muñoz-Carril (2015, p. 148):

...el fenómeno de internet y de las redes sociales no ha hecho más que evidenciar la sobrada capacidad de las personas para colaborar, para aprender entre iguales o bien para elegir los expertos con los que espera aprender. Los propios usuarios de las tecnologías de la información y la comunicación (en adelante TIC) parecen haberse empoderado del potencial de internet para diseminar contenidos y, dejando atrás antiguos prejuicios acerca de la posesión del conocimiento, han conseguido la confianza suficiente para compartir con otros sus habilidades, conocimientos o experiencias, en un proceso de intercambio en el que todos los usuarios pueden ganar algo.

De fato, estabelecer a confiança no potencial das TIC's para o ensino e compartilhar conhecimentos representam transformações que por si mesmas são desafiadoras em qualquer cenário educativo. No caso dos cursos de língua portuguesa em LAT (e das demais línguas estrangeiras, inglês e japonês) ao início do processo de implementação do ensino remoto de emergência, os questionamentos dos professores revelavam suas preocupações acerca de como levar adiante a interação, as avaliações e promover um ambiente colaborativo de forma remota. Por meio de avances institucionais (capacitações e suporte) e esforços individuais e coletivos no desenvolvimento de competências digitais foi possível constatar pequenas mudanças com relação a esta postura. Nessa nova forma de encarar o desafio de um ensino remoto, notou-se inclusive que estudantes pouco participativos se atreviam mais a interagir com seus colegas em aula, perguntar mais e estar nos encontros com uma postura mais ativa. Por outro lado, o esconder-se atrás de telas também facilitou perceber atitudes contrárias. Alunos que preferiam assistir aos conteúdos, como se os encontros virtuais fossem semelhantes a uma sala de aula. Professores que ainda seguiam replicando modelos de aulas expositivas típicos de contextos presenciais, sem reconsiderarem as mudanças de seus programas às aulas online. Obviamente, esses casos representavam extremos, o oposto do que se espera com o emprego de metodologias ativas e com a docência virtual, onde tentar adaptar sessões presenciais a uma hora de encontros virtuais e considerar que a mera exposição a conteúdos poderia ser sinônimo de aprender são práticas incorretas de uso das TIC's, tal como apontam Hernández-Sellés et al (2015). Para esses autores, a antiga forma de conceber os processos de ensino e aprendizagem fundamentados nos conteúdos e centrados nos conhecimentos do professor se diferem das experiências de aprendizagem por meio da interação com o contexto, isto é, a base para que as TIC's se apliquem à docência.

Cada um dos recursos descritos na seção seguinte está enfocado nas experiências resultantes do planejamento da disciplina Gramática Contrastiva Português-Espanhol para o ensino remoto de emergência no $1^{\circ}$ semestre de 2020.

\subsection{Recursos virtuais na aula}

\subsubsection{Padlet}

Padlet é uma ferramenta que permite criar quadros virtuais. A função desses quadros pode estar relacionada com os contextos educacionais ao permitir a organização de materiais de ensino e aprendizagem de forma dinâmica e fácil, por meio de hipervínculos. Além disso, possibilita um grau de interação maior entre professores e estudantes, já que as configurações colocam textos, vídeos, imagens, comentários e apreciações num painel aberto. Dessa forma, seu valor está na disponibilidade de recursos (leituras, vídeos, textos produzidos) e na participação dos estudantes em exposição de dúvidas, interação com os demais usuários e na organização pessoal de materiais (portfolios online).

No contexto da disciplina Gramática Contrastiva Português-Espanhol, destacamos que um Padlet foi 
construído pela professora da disciplina e os estudantes foram incentivados a construir os seus, ainda que não fosse parte das atividades obrigatórias previstas. Suas funções variaram entre:

a) Ferramenta de apoio às aulas: organização de materiais para estudo autônomo: artigos acadêmicos, vídeos, vídeo-aulas, publicidade, dicionários, gramáticas. Os alunos poderiam aceder a esses materiais de forma rápida, navegar pelos diferentes recursos e sugerir outros para que também estivessem vinculados.

b) Instrumento para avaliação formativa sobre a participação dos estudantes: prévio aos encontros sincrônicos por vídeo, os alunos deveriam realizar e comentar brevemente leituras ou vídeos disponibilizados. Ao emitir sua opinião sobre determinado aspecto, eram também incentivados a ler e interagir com os demais estudantes.

c) Motivação para e sistematização de aulas: ao ter acesso a materiais referentes às aulas de forma antecipada, a participação nos encontros sincrônicos se incrementava. Perguntas, opiniões e sugestões eram frequentes. Além disso, atividades como tickets de entrada ou saída das aulas eram incluídas, valorizando a interação imediata e a espontaneidade das respostas acerca do que se pretendia entender ou do que se considerava aprendido.

A Figura 1 a seguir ilustra algumas dessas possibilidades:

\begin{tabular}{|c|c|}
\hline $\begin{array}{l}\text { Um blog, muitos } \\
\text { comentários }\end{array}$ & $\begin{array}{l}\text { Tenho uma pergunta: } \\
\text { Sintaxe }\end{array}$ \\
\hline 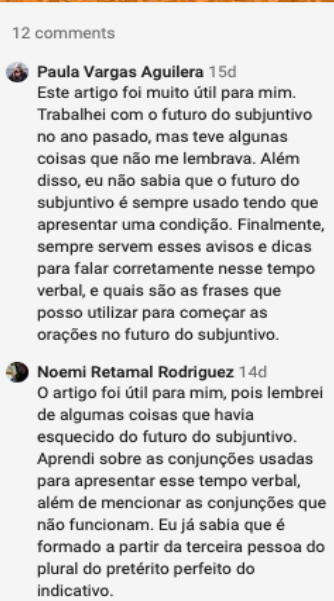 & 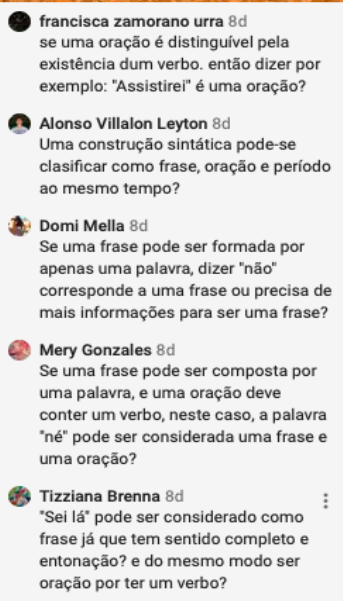 \\
\hline
\end{tabular}

Figura 1: Usos da ferramenta Padlet, captura de tela das interações desenvolvidas na disciplina Gramática Contrastiva Português-Espanhol cedida pela professora

\subsubsection{Miro}

Miro é uma ferramenta que permite a construção conjunta de diagramas, fluxos de informações, mapas conceituais, cronogramas e planejamento de pesquisas. Dessa forma, suas aplicações ao âmbito acadêmico são evidentes. Estudantes e professores elaboram suas ideias, opinam, categorizam, ajustam e apresentam suas propostas. Seu uso também está fundamentado na interação estudantes-estudantes e estudantesprofessor. Essa ferramenta é ideal para a configuração da "sala de aula invertida" ou "flipped classroom", metodologia de ensino em que os estudantes são orientados a sistematizar, desenvolver e elaborar determinada conteúdo com base em trabalhos de pesquisa anteriores e colaboração de seus pares, sendo que o professor passa a ser um guia nesse processo.

Para organizar atividades com o uso da ferramenta Miro é necessário que o professor tenha em mente os resultados de aprendizagem que pretende observar e planeje sua atuação como orientador e apoiador do processo de construção coletiva.

No contexto da disciplina Gramática Contrastiva português-espanhol, destacamos o uso da ferramenta Miro para a construção de um mapa conceitual a partir das pesquisas requeridas para a aula de introdução à sintaxe da língua portuguesa. Os alunos leram artigos, arquivos PowerPoint, capítulos de gramáticas e assistiram a uma vídeo-aula relacionada com o tema.

Uma captura de tela do trabalho realizado é apresentada na Figura 2 a seguir:

Figura 2. Miro 


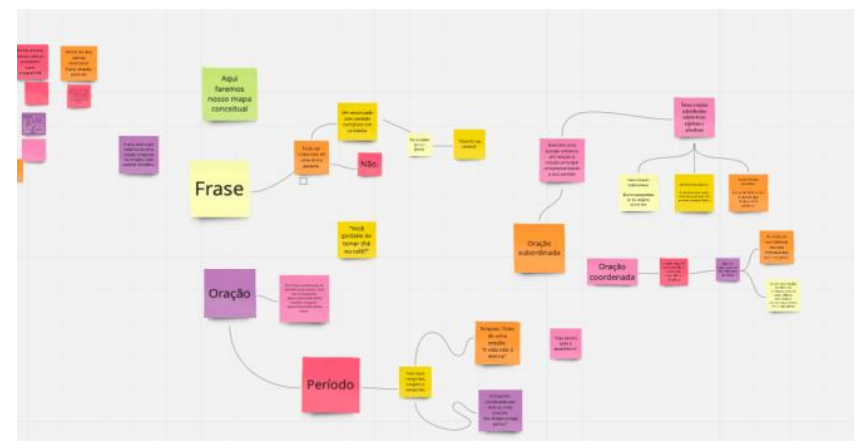

Figura 2. Uso da ferramenta Miro, aula de Introdução à sintaxe, captura de tela de seção virtual da disciplina Gramática Contrastiva PortuguêsEspanhol cedida pela professora

\subsubsection{Discussão online}

A plataforma Moodle oferece o uso do Foro para discussões. Esse recurso permite que os estudantes matriculados na disciplina tenham acesso a essa atividade e se expressem por meio de um chat. A organização da atividade e a forma de avaliar a participação dos estudantes fica a critério do professor. Ao final da atividade, existe a possibilidade de manter um arquivo com a seção de discussão completa. Novamente, é necessário que o professor tenha em mente os resultados de aprendizagem que pretende observar e considere sua atuação como orientador e motivador da discussão, de modo a abrir a conversa, fomentar a participação individual e concluir a atividade, tarefa que pode também ser planejada de modo coletivo ao início da seção.

A experiência de uso do Foro na disciplina Gramática Contrastiva Português-Espanhol foi baseada na tarefa de leitura do texto Por uma língua feminista, de Davi Silva Gonçalves, publicado na revista RICS no ano 2018, como parte da unidade contrastiva substantivos português-espanhol. A participação efetiva dos estudantes e o interesse gerado pelo tema foram pontos a destacar ao longo do Foro. A mescla de usos orais e escritos da língua portuguesa também esteve presente, tal como se espera em interações dessa natureza.

\subsubsection{Avaliação formativa e somativa por} meio de recursos virtuais
Como um dos aspectos mais desafiadores do contexto de ensino remoto de emergência, a avaliação de conteúdos é possível e deve ser cuidadosamente planejada e alinhada com os resultados de aprendizagem da disciplina. Destacamos duas atividades que fizeram parte da disciplina Gramática Contrastiva Português-Espanhol, a apresentação de trabalhos em grupos e a avaliação por pares.

A apresentação de trabalhos ou relatórios de pesquisas por meio de videoconferências ou vídeochamadas com vários participantes tem como suporte uma variedade de plataformas: Meet, Zoom, Teams, entre outras. A interação entre os participantes e suas telas (trabalhos ou anotações) é facilitada. Permitem também a organização de trabalhos em grupos, a interação por chat, a habilitação de microfones e vídeos de modo a controlar as intervenções. Evidentemente, outras funcionalidades são reconhecidas por esses meios, tais como as provas orais (sincrônicas) e as gravações que os estudantes podem realizar com base em algum roteiro ou tarefa. Considerando que as apresentações podem fazer parte de processos de avaliação somativa ou formativa, todo tipo de comentário ou nota deve estar fundamentado em pautas de avaliação previamente conhecidas por todos.

A avaliação por pares possui uma série de configurações, entre enquetes e tarefas (Moodle), jogos (Mentimeter), quadros digitais (Miro) e com o uso de rubricas e dinâmicas de reflexão sobre conhecimentos e habilidades desenvolvidos em determinada tarefa, como o Critical Friend Protocol (Storey e Wang, 2016). Independente da escolha, a prática das atividades de avaliação por pares deve ser parte do desenho das atividades, para evitar que comentários ou notas prejudiquem a interação do grupo. As vantagens do emprego das ferramentas virtuais são evidenciadas para esse tipo de avaliação.

Exemplificamos na Figura 3 a atividade de avaliação em pares desenvolvida com o suporte da plataforma Moodle. Para esta oportunidade, as opiniões dos estudantes acerca dos trabalhos apresentados por videoconferência foram emitidas de forma anônima. 
Figura 3: avaliação por pares

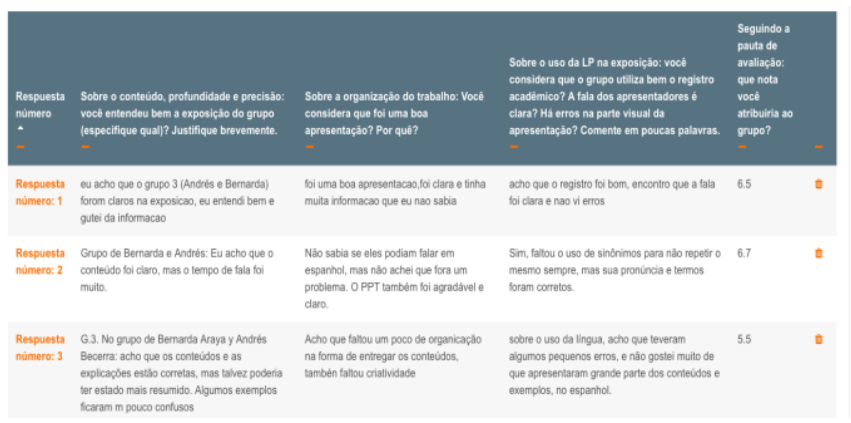

Figura 3: Avaliação em pares de grupos de trabalho, captura de tela de seção virtual da disciplina Gramática Contrastiva Português-Espanhol cedida pela professora

\section{Considerações finais}

Neste artigo, mostramos como o contexto de ensino remoto de emergência tem incrementado 0 letramento digital de professores e estudantes de PLE para estudantes hispanofalantes universitários de tradução. Ao exemplificar o emprego de recursos virtuais para o trabalho docente, evidenciam-se não somente sua funcionalidade e pertinência, segundo os requerimentos contextuais, como também a resistência quanto ao emprego de TIC's. Duas décadas após as primeiras pesquisas e reflexões sobre sua utilidade no ensino de línguas, questionamentos acerca de sua funcionalidade para a interação em aula, para a configuração de avaliações, para a apresentação de conteúdos parecem ainda gerar argumentos reticentes - embora o contexto atual não ofereça tempo para ser contrário ao seu emprego. É assim como encontramos espaço para práticas arraigadas como 0 improviso das interações presenciais, a centralidade do conhecimento na figura do professor e nos conteúdos estáticos das disciplinas e a postura de assistência à aula por parte dos estudantes traspassadas ao ensino remoto de emergência, revelando que ainda temos muito por desenvolver em termos de letramento digital para um adequado aproveitamento da tecnologia na sala de aula virtual de PLE.

Por certo, essa resistência pode ser quebrada à medida que professores e estudantes passam a se envolver com o desenho de cursos e atividades segundo os requerimentos impostos por essa modalidade de ensino. É possível prever também que essa experiência trará modificações às formas como concebemos o ensino e a aprendizagem de línguas no âmbito da educação superior logo de superada a etapa remota emergencial. Conhecidas e estabelecidas as vantagens de ferramentas de interação, exposição e avaliação de conteúdos, as discussões vindouras serão como permanecerá o uso das TIC's em nossas aulas presenciais, possivelmente abrindo espaço à e consolidando a modalidade blended learning. Tal desafio não será apenas um reflexo dessa experiência educativa intensa que marca o ano 2020, mas também o resultado de mudanças nas dinâmicas de trabalho e de interações sociais.

Segundo as perguntas que nortearam nossa exposição até este ponto, i. Em que medida os recursos exemplificados representariam transformações na abordagem de conteúdos de PLE a hispanofalantes? ii. Como os recursos exemplificados relacionam competências acadêmicas, desenvolvimento de língua e letramento digital de professores e estudantes?, consideramos algumas possibilidades de respostas.

Quanto a possíveis transformações na abordagem de conteúdos de PLE a hispanofalantes, devemos pensar que recursos didáticos virtuais reconfiguram os conteúdos, exigem maiores esforços de professores e estudantes quanto à preparação para as aulas e requerem a compreensão da necessidade de aprendizagem constante, não somente no tempo de duração dos encontros virtuais. O planejamento de cursos se vê também obrigado a ajustar-se nessa modalidade, requerendo especial atenção aos resultados de aprendizagem e ao desenho de atividades que ajudarão a alcançá-los. Ao pensar em transformar conteúdos, não estamos nos referindo à sua adaptação, mas sim à sua pertinência em um contexto dinâmico de interação. Assim como já propunha Siemens (2005) acerca do conectivismo, existe uma espécie de ciclo de desenvolvimento de conhecimentos que é sustentado por uma rede: desde o conhecimento individual às organizações e instituições e de volta ao indivíduo, o que "permite que os alunos permaneçam atualizados em seu campo por 
meio das conexões que formaram" (SIEMENS, 2005, p. 6).

Quanto à relação entre competências acadêmicas, desenvolvimento de PLE e letramento digital de professores e estudantes, observamos no contexto de ensino remoto de emergência uma aceleração na inserção de TIC's em nossas práticas acadêmicas diárias, as quais já são parte do âmbito social e laboral. Por um lado, o ensino fundamentado em práticas colaborativas gera experiências de aprendizagem tanto relacionadas com os conteúdos como aquelas próprias do domínio social. Exige-se maior preparação, busca e seleção constante de informações adicionais, presença e transferência do que é aprendido em novas tarefas. As habilidades de compreensão e produção oral e escrita são forçadamente incrementadas, posto que o contexto de interação virtual exige seus usos. A comunicação (em PLE e na língua materna) com os colegas e com o professor deve ser precisa, bem como a capacidade de escutar e gerar novas ideias (HERNÁNDEZSELLÉs et al, 2015). Tudo isso impacta o desenvolvimento de habilidades sociais, como 0 trabalho em equipe e as experiências de receber $e$ oferecer retroalimentação de forma construtiva. Por outro lado, para que isso ocorra, é imperativo assumir a responsabilidade quanto ao letramento digital e ao uso da linguagem em contextos virtuais. Ambas competências devem ser pesquisadas, descritas, praticadas e aprendidas continuamente, tal como as competências acadêmicas de professores e estudantes e a língua em aprendizagem.

Corroborando a ideia de Bubart (2015), recursos para o ensino online, e especialmente, no contexto de ensino remoto de emergência, são muitos e estão em permanente desenvolvimento. O que buscamos exemplificar no presente artigo é apenas uma das possibilidades de configuração desses recursos a um contexto específico de ensino de PLE, reconhecendo que outros modos de explorá-los e aplica-los continuam em aberto. Os desafios que o emprego desses recursos nos propõe se relacionam especificamente com as condições institucionais de docência, com o desenvolvimento do letramento digital, nosso e dos nossos estudantes, e de como ensinar e aprender PLE requerem de um maior compromisso nas interações que pretendemos gerar e nos conteúdos a trabalhar antes, durante e depois de nossas aulas virtuais. Estendo a reflexão ao depois em referência também à acelerada modificação da docência que experimentamos devido à pandemia do Sars-CoV-2. O ensino de línguas no âmbito terciário, de modo particular, terá muito a contribuir para futuras pesquisas nos âmbitos pedagógico e científico, posto que deverá se beneficiar ainda mais com o desenvolvimento de competências digitais tanto aquelas requeridas dos professores como aquelas requeridas dos estudantes.

\section{REFERÊNCIAS}

ALMEIDA FILHO, José Carlos Paes. "Uma metodologia específica para o ensino de línguas próximas? Em: ALMEIDA FILHO, José Carlos Paes de (org.): Português para estrangeiros interface com 0 espanhol. Campinas: Pontes, p. 13-21, 1995.

ALMEIDA FILHO, José Carlos Paes de. "Codificar conteúdos, processo, e reflexão formadora no material didático para ensino e aprendizagem de línguas." Em: PEREIRA, Ariovaldo Lopes; GOTTHEIM, Liliana (Orgs.). Materiais didáticos para o ensino de língua estrangeira - Processos de criação e contexto de uso. Campinas: Ed. Mercado de Letras, p.13-28, 2013.

ALONSO REY, Rocío. El mito de la facilidad en el estudio del proceso de enseñanza y aprendizaje de PLE-HE. Estudios Portugueses, n. 4, p. 11-38, 2004. < https://dialnet.unirioja.es/servlet/articulo?codigo=3727 747> Data de acesso: 19/08/2020.

ALONSO REY, María Rocío. Portugués para hispanohablantes: aspectos teóricos y prácticos de un área emergente de investigación. Estudios Portugueses y Brasileños, n. 12, p. 9-26, 2012. < https://dialnet.unirioja.es/servlet/articulo?codigo $=4680$ 391 > Data de acesso: 19/08/2020

BURBAT, Ruth. El aprendizaje autónomo y las TIC en la enseñanza de una lengua extranjera: ¿Progreso o retroceso? Porta Linguarum, n. 26, p. 37- 
51, jun. 2016. Disponível em: < http://www.ugr.es/ portalin/articulos/PL_numero26/A RT3_Ruth\%20Burbat.pdf > Data de acesso: $19 / 08 / 2020$

COSTA, Fernando A.; PERALTA, Helena. Comunidades virtuales de aprendizaje: el punto de vista de los participantes. Revista Electrónica Teoría de la Educación. Educación y Cultura en la Sociedad de la información, v. 8, n. 3, diciembre 2007. Disponível em:

https://campus.usal.es/ teoriaeducacion/rev_numero_ 08_03/n8_03_albuquerque_peralta.pdf > Data de acesso: 22/08/2020.

DELL'ISOLA, Regina L. P. "Em busca da formação continuada de professores de Português como língua estrangeira: alguns parâmetros". Em: JÚDICE, Norimar (coord.). Ensino da língua e da cultura do Brasil para estrangeiros, Niterói: Intertexto, p. 9-30, 2002.

FERREIRA, Itacira A. "Português/espanhol fronteiras linguísticas que devem ser delimitadas". Em: ALMEIDA FILHO, José Carlos Paes de (Org.): Português para estrangeiros: interface com 0 espanhol, Campinas: Pontes, p. 34-48, 1998.

GRABE, Mark; GRABE, Cindy. Integrating Technology for Meaningful Learning. Boston: Cengage Learning, 2006. 464 p.

GROSSO, Maria José dos Reis; SOARES, Antonio; SOUZA, Fernanda; PASCUAL, José. Quadro de referência para 0 ensino de português no estrangeiro. Documento orientador. DGE MEC Portugal, 2011.

HERNÁNDEZ-SELLÉS, Nuria; GONZÁLEZSANMAMEDY, Mercedes; MUÑOZ-CARRIL, PabloCésar. El rol docente en las ecologías de aprendizaje: análisis de una experiencia de aprendizaje colaborativo en entornos virtuales. Profesorado Revista de curriculum y formación del profesorado, v. 19, n. 2, mayo-agosto, 2015. Disponível em: < https://digibug.ugr.es/bitstream/handle/10481/37369/r ev192ART9.pdf?sequence $=1$ \&isAllowed $=y$ > Data de acesso: 19/08/2020.

HODGES; Charles; MOORE, Stephanie, LOCKEE, Barb; TRUST, Torrey; BOND, Aaron. The
Difference Between Emergency Remote Teaching and Online. Educase Review. Março de 2020. Disponível em: < https://er.educause.edu/articles/2020/3/thedifference-between-emergency-remote-teaching-andonline-learning > Data do acesso: 19/08/2020

JARAMILLO, Patricia. Uso de tecnologías de información en el aula. ¿Qué saben hacer los niños con los computadores y la información?, Revista de Estudios Sociales, 20, Junio 2005. Disponível em: < http://journals.openedition.org/revestudsoc/23700>

Data de acesso: 23/08/2020.

JÚDICE, Norimar. Português para estrangeiros: perspectivas de quem ensina. Niterói: Intertexto, 2002. $106 \mathrm{p}$.

JÚDICE, Norimar. "Módulos didáticos para grupos específicos de aprendizes estrangeiros de português do Brasil: uma perspectiva e uma proposta". Em: PEREIRA, Ariovaldo Lopes; GOTTHEIM, Liliana (Orgs.). Materiais didáticos para o ensino de língua estrangeira - Processos de criação e contexto de uso. Campinas, Brasil: Ed. Mercado de Letras, p. 147-184, 2013.

LEFFA, V. J. A aprendizagem de línguas mediada por computador. In: Vilson J. Leffa. (Org.). Pesquisa em lingüística Aplicada: temas e métodos. Pelotas: Educat, p. 11-36, 2006.

LOTHERINGTON, Heather; JENSON, Jennifer. Teaching Multimodal and Digital Literacy in L2 Settings: New Literacies, New Basics, New Pedagogies. Annual Review of Applied Linguistics, v. 31, p. 226-246, mar. 2011. Disponível em: < https://www.cambridge.org/core/journals/annualreview-of-applied-linguistics/article/teachingmultimodal-and-digital-literacy-in-l2-settings-newliteracies-new-basics-newpedagogies/3272B0C027D5461FA5B23946159B342 A > Data de acesso: 19/08/2020.

MARQUES, Ana Laura S.. Percepções de estudantes de tradução acerca do processo de biletramento. Revista X, v. 12, n. 2, UFPR, p. 105-129, 2017. Disponível em: < https://revistas.ufpr.br/revistax/issue/view/2236 > Data de acesso: 19/08/2020. 
MENDES, Edleise. Diálogos interculturais: ensino e formação em português língua estrangeira. Campinas: Pontes, 2011. 310 p.

PAIVA, Vera. L. Menezes de Oliveira. A WWW e o ensino de inglês. Revista brasileira de linguística aplicada, n.1, p. 93-116, 2001.

RODRIGUES, Jeanne; MUENCHOW, Nicole; RIBAS, Fernanda. A utilização de softwares para o ensino de inglês como L2: o Edilim como ferramenta para promover a aprendizagem na sala de aula invertida. VEREDAS ON-LINE - AS TECNOLOGIAS DIGITAIS NO ENSINO E APRENDIZAGEM DE LÍNGUAS, n. 1, p.21- 39, $2017 . \quad<$ https://www.ufjf.br/revistaveredas/files/2017/09/ARTIG O-2.pdf > Data de acesso: 19/08/2020.

SCHLEPPEGRELL, Mary J.. "Challenges of the science register for ESL students: errors and meaningmaking" Em SCHLEPPEGRELL, Mary J.; COLOMBI, M. Cecilia (Coord.), Developing advanced literacy in first and second languages, New York: Routledge, p. 119-142, 2002.

SCHLEPPEGRELL, Mary J.. The language of schooling: A functional linguistic perspective. New Jersey, Lawrence Erlbaum, 2004. 190 p.

SIEMENS, George. Connectivism: A learning theory for the digital age. ITDLL Journal, v. 01, p. 1-9, jan. 2005. Disponível em: < https://jotamac.typepad.com/jotamacs_weblog/files/C onnectivism.pdf > Data de acesso: 19/08/2020.

SILVA, Ismael de Sousa da. O uso das TIC pelos professores e alunos Centro de Estudos Brasileiros (Asunción, Paraguay), dentro do contexto educativo e social como ferramentas complementares no processo ensino-aprendizagem de PLE. Revista Vozes dos Vales, UFVJM, n. 4, ano II, out. 2013. Disponível em:

http://site.ufvjm.edu.br/revistamultidisciplinar/files/201 4/03/O-uso-das-TIC-pelos-professores-e-alunosCentro-de-Estudos-Brasileiros-Asunción-

Paraguay.pdf > Data de acesso: 19/08/2020.

STOREY, Valerie; WANG, Victor C. X. Critical Friends Protocol: Andragogy and Learning in a Graduate Classroom. Sage Journals, v. 28, issue: 3, p. 107-114, 2016. Disponível em: < https://journals.sagepub.com/doi/abs/10.1177/104515 9516674705 > Data de acesso: 19/08/2020.

TOUR, Ekaterina. Digital mindsets: Teachers' technology use in personal life and teaching. Language Learning \& Technology, 19(3), p. 124-139, 2015, out. 2015. Disponível em: < https://www.Iltjournal.org/item/2923 > Data de acesso: 19/08/2020.

TUMOLO, Celso. Recursos digitais e aprendizagem de inglês como língua estrangeira. Revista Ilha do Desterro, n. 66, p. 203-238, Florianópolis, jan/jun 2014. Disponível em: $<$ https://www.scielo.br/scielo.php?script=sci_arttext\&pi $\mathrm{d}=\mathrm{S} 2175-80262014000100203$ > Data de acesso: 22/08/2020.

UNITED NATIONS EDUCATIONAL, SCIENTIFIC AND CULTURAL ORGANIZATION. Analytical Survey. Information and communication technologies in the teaching and learning of foreign languages and perspectives. UNESCO Institute For Information Technologies In Education, Moscow, 2004. Disponível em:

https://unesdoc.unesco.org/in/documentViewer.xhtml? $\mathrm{v}=2.1$.196\&id=p::usmarcdef_0000139195\&file=/in/rest /annotationSVC/DownloadWatermarkedAttachment/at tach_import_fe01f1bc-4667-42cc-a3ad-

2a7335c96c3a\%3F_\%3D139195engo.pdf\&locale=en \&multi=true\&ark=/ark:/48223/pf0000139195/PDF/139 195engo.pdf\#\%5B\%7B\%22num\%22\%3A62\%2C\%22 gen\%22\%3A0\%7D\%2C\%7B\%22name\%22\%3A\%22X YZ\%22\%7D\%2Cnull\%2Cnull\%2C0\%5D > Data de acesso: 19/08/2020

MARQUES, Ana Laura dos Santos. Competências digitais e práticas de ensino de PLE a hispanofalantes em contexto universitário online de emergência. Signo, Santa Cruz do Sul, v. 46, n. 85, p. 70-82, jan. 2021. ISSN 1982-2014. Disponível em:

<https://online.unisc.br/seer/index.php/signo/article/view/156 68. doi:https://doi.org/10.17058/signo.v46i85.15668. 